\title{
Exploring the utility of Brachypodium distachyon as a model pathosystem for the wheat pathogen Zymoseptoria tritici
}

\author{
Aoife O'Driscoll ${ }^{1,2}$, Fiona Doohan ${ }^{2}$ and Ewen Mullins ${ }^{1 *}$
}

\begin{abstract}
Background: Zymoseptoria tritici, the causative organism of Septoria tritici blotch disease is a prevalent biotic stressor of wheat production, exerting substantial economic constraints on farmers, requiring intensive chemical control to protect yields. A hemibiotrophic pathogen with a long asymptomless phase of up to 11 days post inoculation (dpi) before a rapid switch to necrotrophy; a deficit exists in our understanding of the events occurring within the host during the two phases of infection. Brachypodium distachyon has demonstrated its potential as a model species for the investigation of fungal disease resistance in cereal and grass species. The aim of this study was to assess the physical interaction between Z. tritici (strain IPO323) and B. distachyon and examine its potential as a model pathosystem for $Z$. tritici.

Results: Septoria tritici blotch symptoms developed on the wheat cultivar Riband from $12 \mathrm{dpi}$ with pycnidial formation abundant by $20 \mathrm{dpi}$. Symptoms on B. distachyon ecotype Bd21-1 were visible from $1 \mathrm{dpi}$ : characteristic pale, water soaked lesions which developed into blotch-like lesions by $4 \mathrm{dpi}$. These lesions then became necrotic with chlorotic regions expanding up to $7 \mathrm{dpi}$. Sporulation on B. distachyon tissues was not observed and no evidence of fungal penetration could be obtained, indicating that $Z$. tritici was unable to complete its life cycle within $B$. distachyon ecotypes. However, observation of host responses to the $Z$. tritici strain IPO323 in five B. distachyon ecotypes revealed a variation in resistance responses, ranging from immunity to a chlorotic/necrotic phenotype.

Conclusions: The observed interactions suggest that $B$. distachyon is an incompatible host for $Z$. tritici infection, with STB symptom development on $B$. distachyon comparable to that observed during the early infection stages on the natural host, wheat. However first visible symptoms occurred more rapidly on B. distachyon; from 1 dpi in comparison to $12 \mathrm{dpi}$ in wheat. Consequently, we propose that the interaction between $B$. distachyon and Z. tritici as observed in this study could serve as a suitable model pathosystem with which to investigate mechanisms underpinning an incompatible host response to $Z$. tritici.
\end{abstract}

Keywords: Brachypodium distachyon, Zymoseptoria tritici, Septoria tritici blotch, wheat

\section{Background}

Wheat is grown on more land area than any other commercial crop in the world and it is the third most produced global cereal after rice and maize. Wheat is susceptible to multiple pathogens, including $Z$. tritici, the causal agent of Septoria tritici blotch (STB) disease. This disease requires intensive chemical control to protect yields. The cost to U.S. growers is estimated at $\sim \$ 275$ million

\footnotetext{
* Correspondence: ewen.mullins@teagasc.ie

'Department of Crop Science, Teagasc Research Centre, Oak Park, Carlow, Ireland

Full list of author information is available at the end of the article
}

annually (http://jgi.doe.gov/why-sequence-mycosphaerella). In Europe, STB represents the greatest threat to wheat production with approximately $70 \%$ (>€400 M) of annual fungicide input directed towards preventing or reducing STB induced losses [1].

The physical infection process of wheat by $Z$. tritici has been previously well characterised [2-6]. With no specialised structures such as appressoria or haustoria for penetration of host tissues [4], Z. tritici infects solely via host stomatal cavities, with penetration occurring within $12 \mathrm{~h}$ (h) post-inoculation. Infecting hyphae grow exclusively intercellularly, advancing into the mesophyll 
layer with a minimal increase of in planta fungal biomass required before the onset of host cell death $[7,8]$. Between 12-20 dpi, Z. tritici switches to an aggressive necrotrophic lifestyle that leads to the characteristic lesions bearing spore-producing pycnidia along the leaf surface. Wheat promptly recognises the presence of $Z$. tritici, with transcriptional changes in defence-gene expression (e.g., PR proteins) recorded from as early as $6 \mathrm{~h}$ after inoculation [9], as well as rapid changes in host cell reactive oxygen species (ROS) during interactions with both virulent and avirulent isolates of the pathogen [6-8]. Mechanisms of susceptibility to $Z$. tritici are now better understood, with susceptible interactions acting as a primary source of information to date [6-13]. Evidence from such studies suggest that $Z$. tritici requires the activation of host cell death signalling pathways and disease lesion formation to acquire sufficient energy to reproduce asexually $[6,7,11]$. Yet despite extensive studies, hypersensitive response (HR)-like cell death has not been associated with a resistant interaction $[2,4,6,9]$ as confirmed by the classic symptoms of PCD occurring during symptom development in the susceptible interaction but not so in the resistant $[7,11]$. It has been hypothesised that the lack of such activity in the resistant interaction is a consequence of more powerful upstream defence responses [1]. If so, what are these responses and do they occur during the early, biotrophic phase of this host-pathogen interaction?

Fully elucidating the host responses of wheat to $Z$. tritici is crucial to the understanding of how resistance, or lack thereof, to the pathogen operates. However because of its complex genome and long generation time, it remains a challenge to conduct in depth 'omic' studies in wheat [14]. Although, rapid developments have been made in the sequencing of the wheat genome $[15,16]$, a deficit in genome annotation means that the interaction between wheat and $Z$. tritici will remain difficult to characterise genetically for the immediate future. A model pathosystem in which the host has been genetically characterised and is amenable to $Z$. tritici infection could act as an integral resource in the quest to answer some of the essential questions surrounding the manifestation of host resistance to $Z$. tritici. The insight gained using Arabidopsis thaliana as a model plant has allowed fundamental questions to be answered for a range of host-pathogen interactions [17-19] but to date no evidence exists that this plant can act as a host for Z. tritici.

B. distachyon has the potential to serve as such an alternative model system, having diverged from the Triticae between 35 and 40 million years ago (MYA) [20]. Although the closest relative to wheat is barley, which diverged from the Tritici between 10-15 MYA [21], B. distachyon remains more closely related to the Triticae family than rice or other sequenced grasses such as sorghum and maize, which diverged from the Triticae $~ 50$ MYA [22]. $B$. distachyon has been described as a model plant for functional genomics in grasses for several reasons [23]: it possesses a relatively small genome with very little repetitive DNA, exhibits a low degree of DNA methylation and has a nuclear genome indistinguishable in size to that of A. thaliana, making it the simplest described genome of the grasses. Other desirable physiological attributes include a small stature, a short lifecycle, simple growth and handling requirements and an established transformation system [24]. In addition, an international effort has ensured that adequate resources for $B$. distachyon have been developed to provide seed stocks and genomics resources (www.brachypodium.org). Owing to these developments, the number of publications detailing the interaction between $B$. distachyon and many of the world's most economically important cereal pathogens, including Fusarium graminearum, Puccinia striiformis, Magnaporthe grisea, Bipolaris sorokiniana, Oculimacula spp., Ramularia collo-cygni and most recently Staganospora nodorum has risen steadily over the last ten years [14,24-32]. The aim of this study was to assess the prospect of employing $B$. distachyon as a tractable pathosystem with which to comparatively investigate host defence mechanisms in the wheat-Z. tritici interaction.

\section{Methods \\ Fungal material}

The Z. tritici (teleomorph Mycosphaerella graminicola) isolate IPO323 has proven to be the isolate of choice for many host-pathogen studies conducted to date $[4,6,8,10$, $11,13,33,34]$ and its preference as a reference isolate is evident by the publication of its sequenced genome in 2011 [35]. For this study, pycnidiospores of isolate IPO323 were stored at $-70^{\circ} \mathrm{C}$ in $10 \%$ glycerol $\left(\mathrm{v} / \mathrm{v}^{-1}\right)$. Prior to use, the isolate was cultured on potato dextrose agar (PDA) and grown at $18^{\circ} \mathrm{C}$ under a $12 \mathrm{~h}$ light/ $12 \mathrm{~h}$ of near ultraviolet (NUV) darkness at $18^{\circ} \mathrm{C}$ for 7 days. Fungal spores for plant inoculation were harvested from these cultures into a $0.05 \%$ Tween 20 solution $\left(\mathrm{v} / \mathrm{v}^{-1}\right.$ sterile distilled water $(\mathrm{SDW}))$ before the spore concentration was adjusted to $1 \times 10^{6} \mathrm{ml}^{-1}$.

\section{Plant material and ecotypes}

Seed of five B. distachyon inbred lines, designated by the prefix "Bd" were provided by Dr. Carl Ng (University College Dublin) and Prof. David Garvin (University of Minnesota). These inbred lines; Bd1-1, Bd12-3, Bd21-1, Bd29-1 and Bd30-1 were developed by single seed descent from NPGS accessions obtained from the USDA Western Regional Research Centre in Albany, CA and the USDA Midwest Area, Plant Science Research Unit at the University of Minnesota, St. Paul, MN. 


\section{Disease trials}

For cultivation, seeds were stratified at $4{ }^{\circ} \mathrm{C}$ for 5 days (with the exception of Bd1-1 where seeds were stratified for 8 weeks) then incubated in darkness at $23^{\circ} \mathrm{C}$ for 5 days to allow germination. Germinated seeds were transferred to $8 \times 8 \times 8 \mathrm{~cm}$ pots and placed in a controlled environment glasshouse, under a $16 \mathrm{~h}$ day/8 $\mathrm{h}$ night cycle at $23 / 12^{\circ} \mathrm{C}$, respectively. One week prior to inoculation with the Z. tritici isolate IPO323; plants were transferred to an $18 / 12^{\circ} \mathrm{C}$ environment to allow acclimatisation to the optimum temperature required for $Z$. tritici infection. Plants were watered every 2 days and each day of the week before planned inoculations took place.

Once plants had reached the five leaf stage, whole $B$. distachyon plants were sprayed with a pycnidial suspension of IPO323 amended with a $0.05 \%$ Tween 20 solution $(\sim 5 \mathrm{ml})$ using a hand-held spray bottle. Control plants were inoculated with the same volume of a $0.05 \%$ Tween 20 solution. Treated plants were covered with polythene bags for 7 days to ensure high humidity. For initial studies on Bd21-1, experiments were conducted three times with 7 technical replicates (a technical replicate represented the fifth leaf of an individual plant) in each experiment. For studies on variations within ecotypes, the experiment was conducted three times with 8 technical replicates for each ecotype. Symptom progression was recorded at 1,4 and $7 \mathrm{dpi}$ with reaction types classified as (i) no symptoms, (ii) patches of yellow and red chlorosis, (iii) chlorosis with necrotic lesions or spots or (iv) necrosis with no symptoms of chlorosis, since the physiology of observed symptoms varied according to the ecotypes screened. The wheat variety Riband, inoculated at the two leaf stage was included as a positive control in initial experiments with $\mathrm{Bd} 21-1$ to ensure $Z$. tritici spore viability and isolate virulence. The sole alteration to experimental conditions for Riband was that the bags were left on for 14 days to maintain humidity to support infection. Disease symptoms were recorded every 2-3 days from $12 \mathrm{dpi}$ up to $31 \mathrm{dpi}$.

In attempts to re-isolate $Z$. tritici from infected leaf tissues, two different procedures were used. Eight inoculated leaves from each ecotype were detached from whole individual plants at $14 \mathrm{dpi}$ by which time they had completely senesced and no further signs of symptom progression could be observed. The leaves were surface sterilised in $70 \%$ ethanol for $10 \mathrm{sec}$ followed by $5 \%$ sodium hypochlorite for 1 minute and rinsed three times in SDW. Leaves were gently dried using a paper towel and placed on water agar amended with streptomycin $\left(50 \mathrm{mgl}^{-1}\right)$ and penicillin $\left(50 \mathrm{mgl}^{-1}\right)$ to eliminate bacteria and mold contamination according to [36]. Leaves were incubated under 12 hours of NUV at $18^{\circ} \mathrm{C}$ for 96 hours, to encourage cirri emergence. Using a Zeiss Stemi DV4 light microscope and a sterile needle, leaves were examined for globose structures resembling pycnidia. In the second pursuit, the experimental design, sterilisation and incubation of the leaves were the same, however instead of attempting to isolate pycnidia using a microscope, sterile leaves were centrifuged at $13,000 \mathrm{~g}$ in a $2 \mathrm{ml}$ Eppendorf tube containing 50ul of SDW, for 30 seconds. The resulting pellet was streaked onto the surface of a PDA plate amended with the above antibiotics. The plates were sealed with parafilm and incubated for seven days after which they were examined for any evidence of Z. tritici growth.

\section{Microscopic analysis}

Bd leaf sections were cleared in $70 \%$ ethanol at room temperature for $24 \mathrm{~h}$ to remove chlorophyll. To detect $\mathrm{H}_{2} \mathrm{O}_{2}$, leaf samples were placed in $1 \mathrm{mg} \mathrm{ml}^{-1} 3,3^{\prime}$ diaminobenzadine (DAB-HCL) (Sigma Aldrich, UK) pH 3.8, according to the protocol described by [6]. For observations of fungal structures, cleared leaf samples were stained at room temperature for four hours in Trypan blue (Sigma Aldrich, UK) in lactoglycerol (1:1:1, lactic acid: glycerol: $\left.\mathrm{H}_{2} \mathrm{O}_{2}\right)$ and rinsed in chloral hydrate $\left(2.5 \mathrm{~g} \mathrm{ml}^{-1}\right)$. Samples were mounted in $40 \%$ glycerol and examined for the presence of hyphal penetration within stomata. Thirty individual leaf samples were examined with 10 stomata assessed per inoculated leaf and viewed across three separate focal planes to detect for evidence of fungal attachment and/or entry into the stomatal cavity. Samples were viewed with a Leica DM 2500 microscope and photographed with a Sony AS400 digital camera.

\section{Results}

The wheat cultivar Riband developed pale water soaked lesions at $12 \mathrm{dpi}$, becoming chlorotic by $14 \mathrm{dpi}$ (Figure 1a, b). Necrotic lesions bearing pycnidia were visible from $17 \mathrm{dpi}$ (Figure 1c), with pycnidial formation abundant by $20 \mathrm{dpi}$ (Figure 1d), continuing to develop up to $31 \mathrm{dpi}$ by which time the leaf had fully senesced (Figure 1e). Leaves of Bd21-1 demonstrated pale, water soaked lesions at $1 \mathrm{dpi}$ (Figure 1f). By $4 \mathrm{dpi}$, these lesions had become chlorotic in appearance with brown necrotic blotch like regions appearing at $7 \mathrm{dpi}$ (Figure $1 \mathrm{~g}, \mathrm{~h}$ ). Lesions continued to expand across the leaf surface up to $14 \mathrm{dpi}$ (Figure 1i). By 21 dpi, leaves had fully senesced, bearing tissue which was almost completely necrotic (Figure 1j). The symptoms on $B$. distachyon were eminently comparable to those observed during the early biotrophic phase of $Z$. tritici infection (Figure 1, compare panels a-e to panels $\mathrm{f}-\mathrm{j}$ ). STB symptoms were observed on all aerial parts of the $B$. distachyon plant including the trichomes, florets, stems and stem nodes (Figure $2 \mathrm{a}-\mathrm{d}$ respectively). No evidence of other disease symptoms from other foliar pathogens were observed in the wheat or Brachypodium controls (data not shown). 


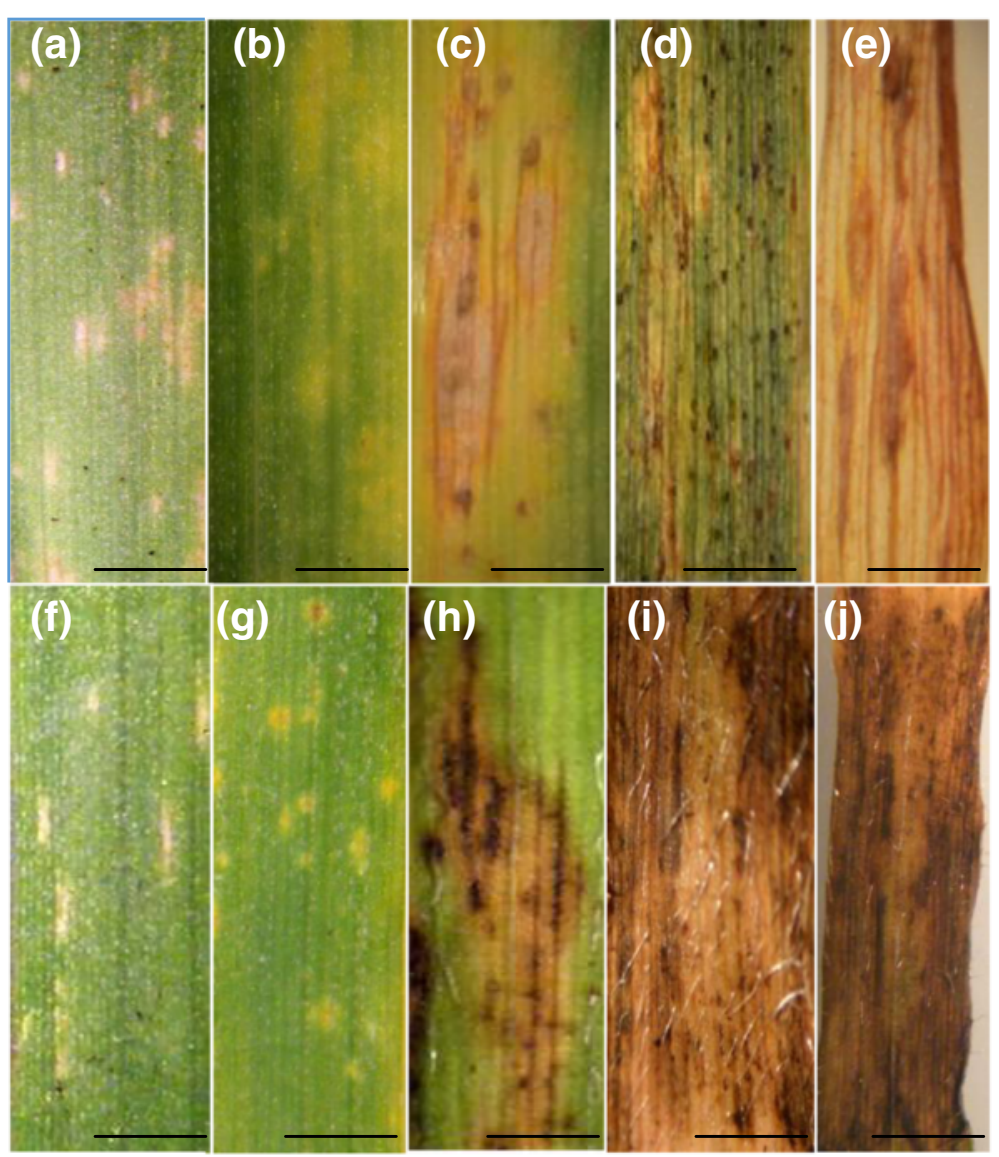

Figure 1 Septoria tritici blotch symptoms on the wheat cultivar Riband and the B. distachyon ecotype Bd21-1. (a-e) Symptoms were recorded on wheat at 12, 14, 17, 20 and 31dpi respectively. (f-j) Symptoms were recorded on Bd21-1 at 1, 4, 7, 14 and 21 dpi. Scale bars=0.5 cm.

A histological examination for evidence of fungal penetration as well as the presence of $\mathrm{H}_{2} \mathrm{O}_{2}$ was undertaken for $B$. distachyon leaf samples harvested at $7 \mathrm{dpi}$. Hyphae were noted to aggregate at leaf veins and traverse the leaf surface (Figure 3a). The production of $\mathrm{H}_{2} \mathrm{O}_{2}$ was associated with the site where fungal hyphae came into contact with host leaf veins as well as adjacent cells (Figure 3b, at), which corresponds with what was observed in Figure 2a where necrotic tissue developed along leaf veins. As expected $Z$. tritici hyphae exhibited brown colouration also (Figure 3b, hp). Hyphae associated with the base of trichomes stained heavily for necrosis (Figure 3a, tr), growing across the inoculated leaf surface (Figure 3a, hp). This correlates with observations in Figure $2 \mathrm{a}, \operatorname{tr}$ where necrotic trichomes were frequently observed on pathogen infected tissues. Hyphae were observed growing towards and around stomatal apertures (Figure 3a, st), attaching to the stoma from the trichome (Figure 3e, tr and hp). Stomata and stomatal apertures with no evidence of fungal attachment or attempted penetration did not stain for hydrogen peroxide or fungal deposition (Figure 3c), in contrast to Figure 3a, en where stomata stained for the presence of fungal deposition and Figure $3 \mathrm{~d}$ where the stomata stained heavily for hydrogen peroxide; likely as a result of the elicitation of a defence response following contact with the fungal pathogen.

\section{Differential ecotype response}

Varying degrees of symptoms and symptom progression were observed within the five $B$. distachyon ecotypes tested (Figure 4a-e). Overall symptom scores were highest for Bd30-1 (Figure 5). The rate of symptom progression was greatest up to $4 \mathrm{dpi}$, with $\mathrm{Bd} 30-1$ showing an $82.5 \%$ increase between 1 and 4 dpi. Between 4 and 7 dpi, symptom progression was impeded, with less than half the rate observed for Bd30-1 between 1 and 4 dpi. The fastest rate of symptom progression between 4 and 7 dpi was in Bd29-1 (46.9\%) (Figure 5). All ecotypes with the exception of Bd1-1 developed similar symptoms at 1dpi (Figure 5) and reaction types followed a pattern of necrotic lesions or spots surrounded by chlorosis 

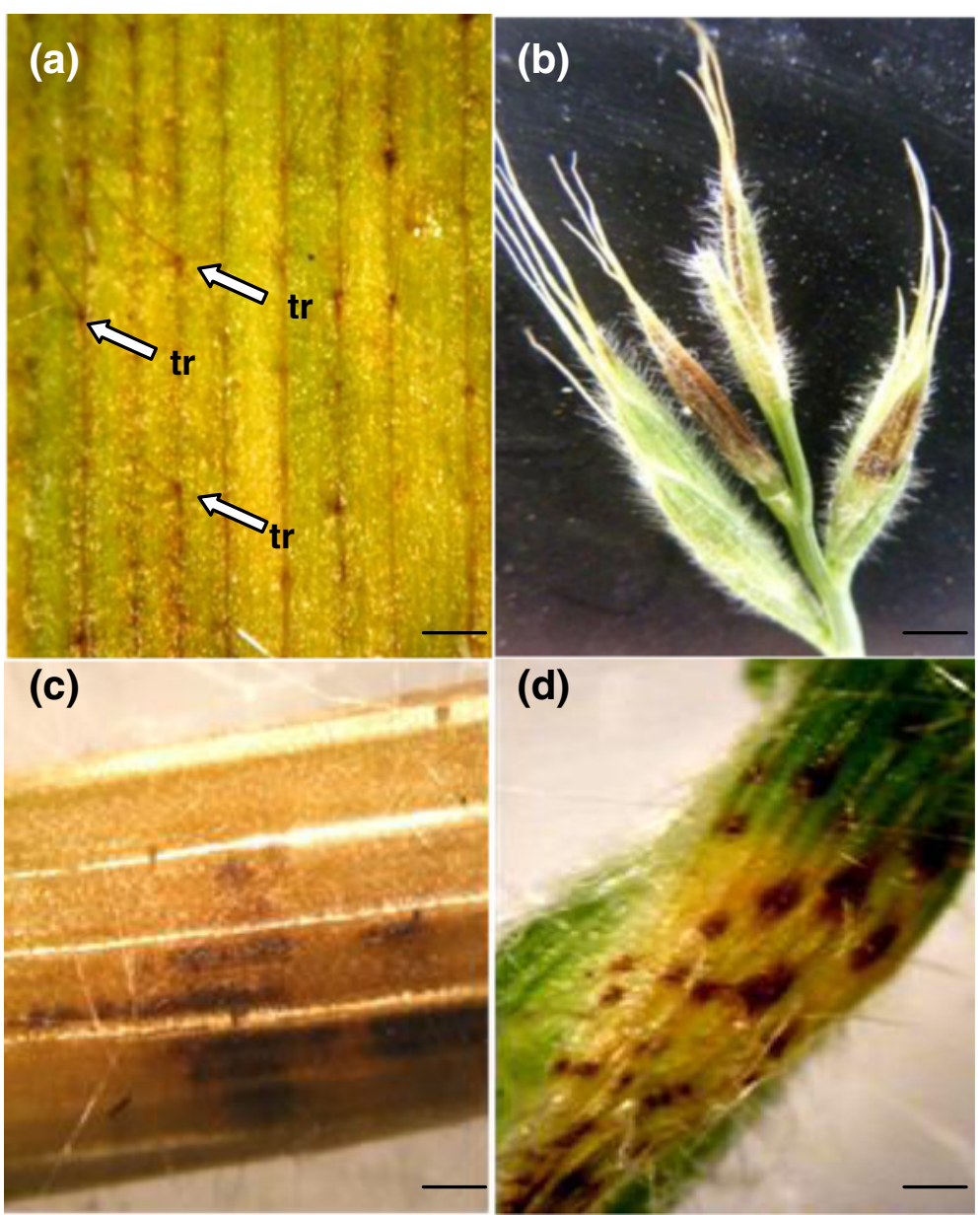

Figure 2 Septoria tritici blotch symptoms on aerial tissues of the $B$. distachyon ecotype Bd21-1. (a-d) Infection symptoms were visible as chlorotic/necrotic phenotypes on trichomes (tr), floral heads, stems and stem nodes respectively. 5 cale bars $=0.5 \mathrm{~cm}$.

(Figures 4b-e and 6), however for Bd12-3, Bd21-1 and Bd29-1, 25\%, 20.83\% and 37.5\% of the plants showed symptoms of red/yellow chlorosis only (Figure 6). For Bd30-1, all plants developed necrotic lesions, with 58.33\% of the plants showing necrotic lesions (Figure 6). Bd1-1 was recorded to be completely symptomless (Figures $4 \mathrm{a}, 5$ and 6) for the duration of the host-pathogen interaction. This lack of symptoms was maintained despite attempts at different methods of inoculation including physical disruption of tissues prior to inoculation (data not shown).

Sporulation was not recorded on any of the five ecotypes tested, with no pycnidia observed on tissues examined under a dissecting microscope. Similarly, the agitation of treated tissues in water did not yield any signs of $Z$. tritici growth following cultivation of the resulting eluate on PDA.

\section{Discussion}

The present study was designed to explore the potential of using $B$. distachyon as a model host for $Z$. tritici and decipher whether this interaction might serve as a contemporary pathosystem to study mechanisms of resistance to $Z$. tritici in wheat. Phenotypically, STB symptoms in $B$. distachyon closely resembled those reported during an incompatible interaction with wheat. Initial symptoms manifested in the form of pale water soaked lesions, followed by the development of necrotic blotchlike lesions surrounded by areas of chlorosis. Significantly, sporulation could not be achieved and stomatal penetration could not be determined, indicating that $B$. distachyon is an incompatible host for $Z$. tritici (strain IPO323) infection. Z. tritici-related symptoms were evident on aerial parts of $B$. distachyon also, most notably the florets. In natural epidemics, STB infection of wheat heads is not frequently observed [37]. While glumes of wheat plants sometimes exhibit STB symptoms [38], attempts to isolate $Z$. tritici from seeds produced either on naturally infected plants [39] or following artificial head infections [40] have failed. After inoculation of adult wheat heads with $Z$. tritici, [41] was able to detect the 


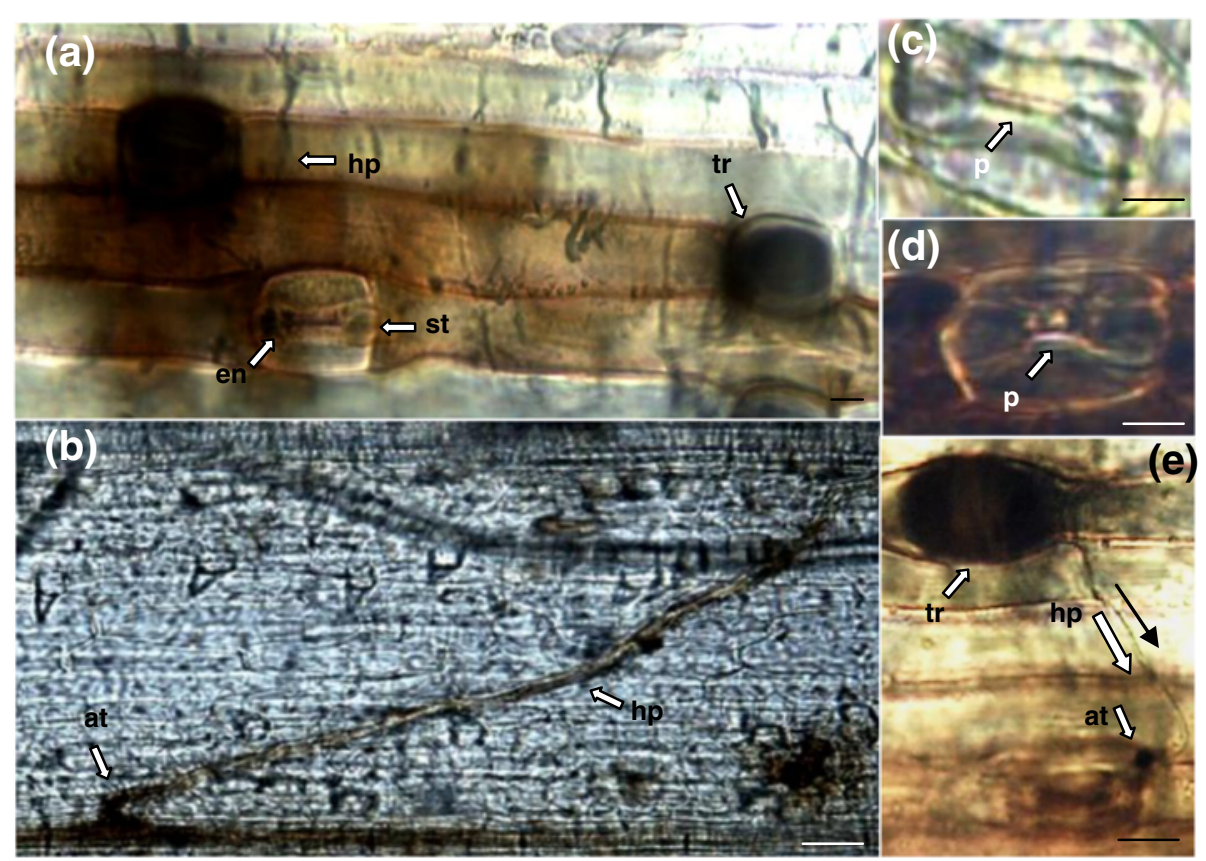

Figure 3 Light microscopy analysis of leaves of the B. distachyon ecotype Bd21-1, cleared and stained with Trypan Blue and DAB. (a) Fungal hyphae visible on leaf surface (hp), with $\mathrm{H}_{2} \mathrm{O}_{2}$ released from cells surrounding a stomata (st), Trypan blue staining is localised in the pore of the stomata (en, st) indicating the presence of fungal tissue. The bases of trichomes (tr) also stain heavily for necrotic tissue. (b) Hyphal attachment (at) at the junction between adjacent vascular tissues showing $\mathrm{H}_{2} \mathrm{O}_{2}$ production within the hyphae (hp) and at the site of attachment. Scale bars (a and $b)=0.5 \mathrm{~mm}$ (c) Uninfected stomata with clear pore (p) and no evidence of fungal staining. (d) Stomata with clear pore (p) and has not stained for fungal tissue, however $\mathrm{H}_{2} \mathrm{O}_{2}$ is present around the circumference of the stomata. (e) Fungal hyphae (hp) originating from the base of a trichome (tr), attaching to the periphery of the stomata (at). Scale bars (c-e) $=0.1 \mathrm{~mm}$

fungus by microscopic observation on only $5 \%$ of the grains. These findings were corroborated by the first detection of naturally contaminated wheat seeds through PCR analysis [42], but the accurate localisation of the pathogen in the seed could not be confirmed. Thus, the presence of disease symptoms on $Z$. tritici infected florets of Bd21-1 is a curious finding.

Studies which highlight the host specificity of $Z$. tritici exist from as early as 1901 [43]. Yet, limited reports have been published since then on the interaction of $Z$. tritici

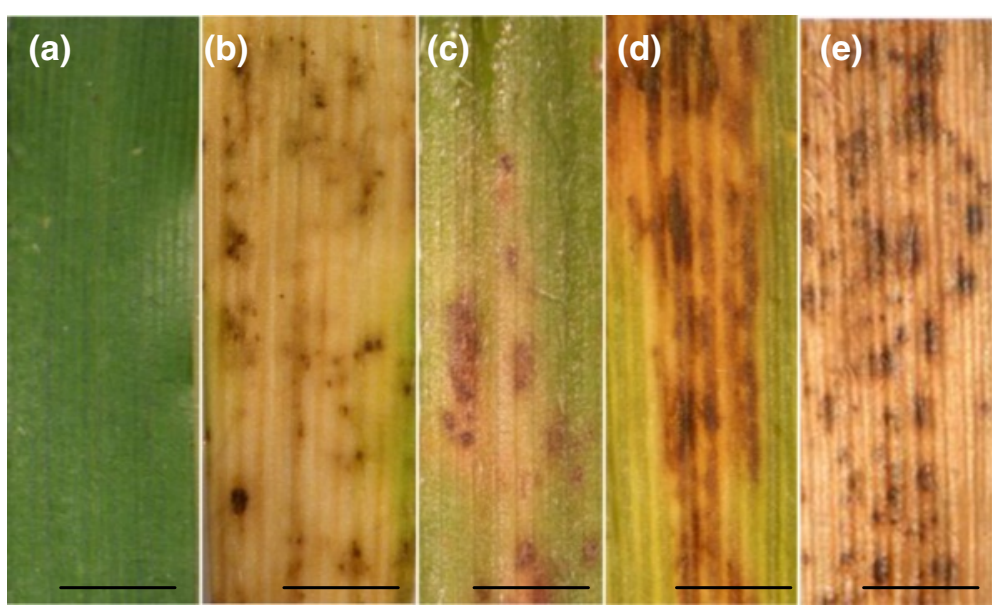

Figure 4 Differential responses between the B. distachyon ecotypes Bd1-1, Bd12-3, Bd21-1, Bd29-1 and Bd30-1 following inoculation with Z. tritici at 7dpi. Typical symptoms for each ecotype were (a) no disease for Bd1-1, (b) chlorosis with little or no development of necrotic lesions on Bd12-3, necrotic lesions surrounded by patches of yellow/red chlorosis for (c) Bd21-1 and (d) Bd29-1 and (e) large patches of predominately necrotic lesions under senescent tissue or green leaf material for Bd30-1. Scale bars $=0.5 \mathrm{~cm}$ 


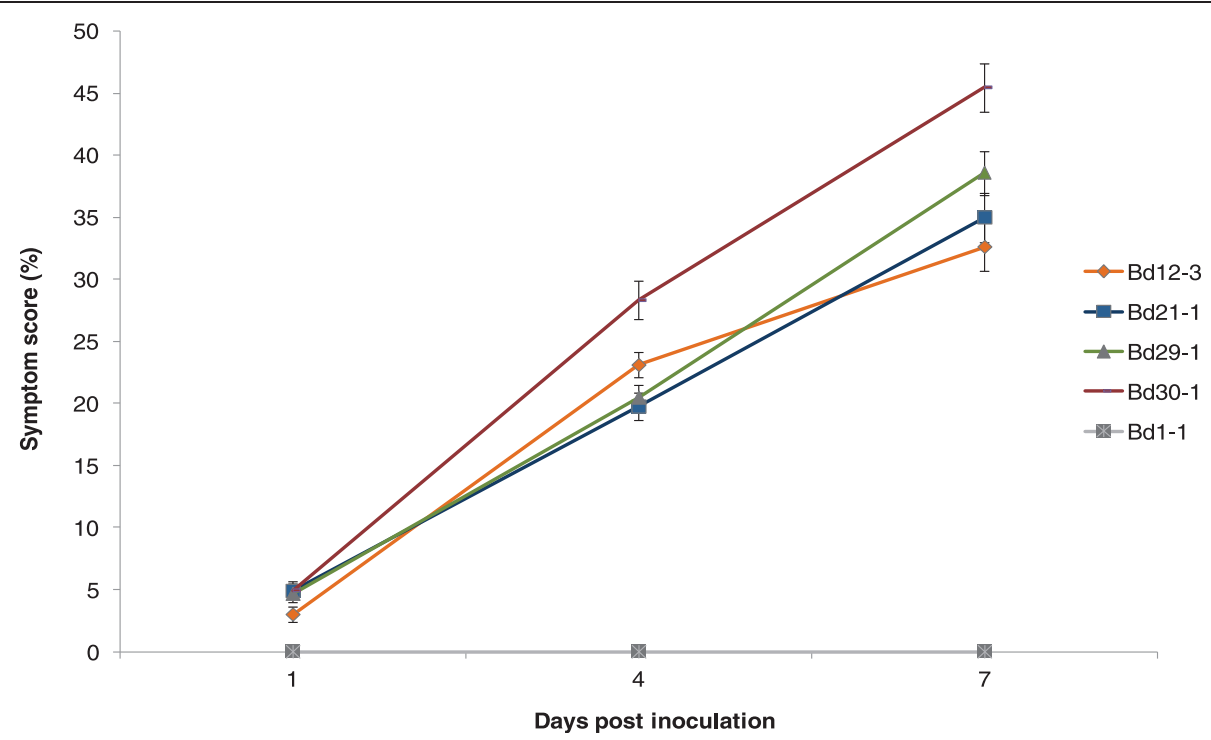

Figure 5 Progression of symptoms for B. distachyon ecotypes Bd12-3, Bd21-1, Bd29-1, Bd30-1 and Bd1-1 following inoculation with Z. tritici. Symptom score determined as \% of leaf tissue affected by symptoms (from either/all 4 symptom classes) at 1, 4 and $7 \mathrm{dpi}$. Means \pm se were calculated from three biologically replicated experiments, where $n=24$.

with other species aside from its natural host, Triticum aestivum. It has been suggested by [44] that Bromus, Agrostis, Agropyron, Brachypodium, Dactylis, Festuca, Glyceria, Hordeum, Poa, Secale cereale and Triticum species were alternative hosts for overwintering $Z$. tritici. However, no concrete evidence has been provided to support this hypothesis. A study by [45] where 25 cereal and grass species were inoculated with $Z$. tritici showed that the fungus infected T. aestivum, T. durum, T. dicoccum and $T$. compactum, but did not infect any other species of the cereals or grasses tested. A comprehensive study by [46] described in detail the interaction between $Z$. tritici and einkorn wheat (T. monococcum), a diploid relative of T. aestivum. Out of 216 interactions tested, $98.6 \%$ were

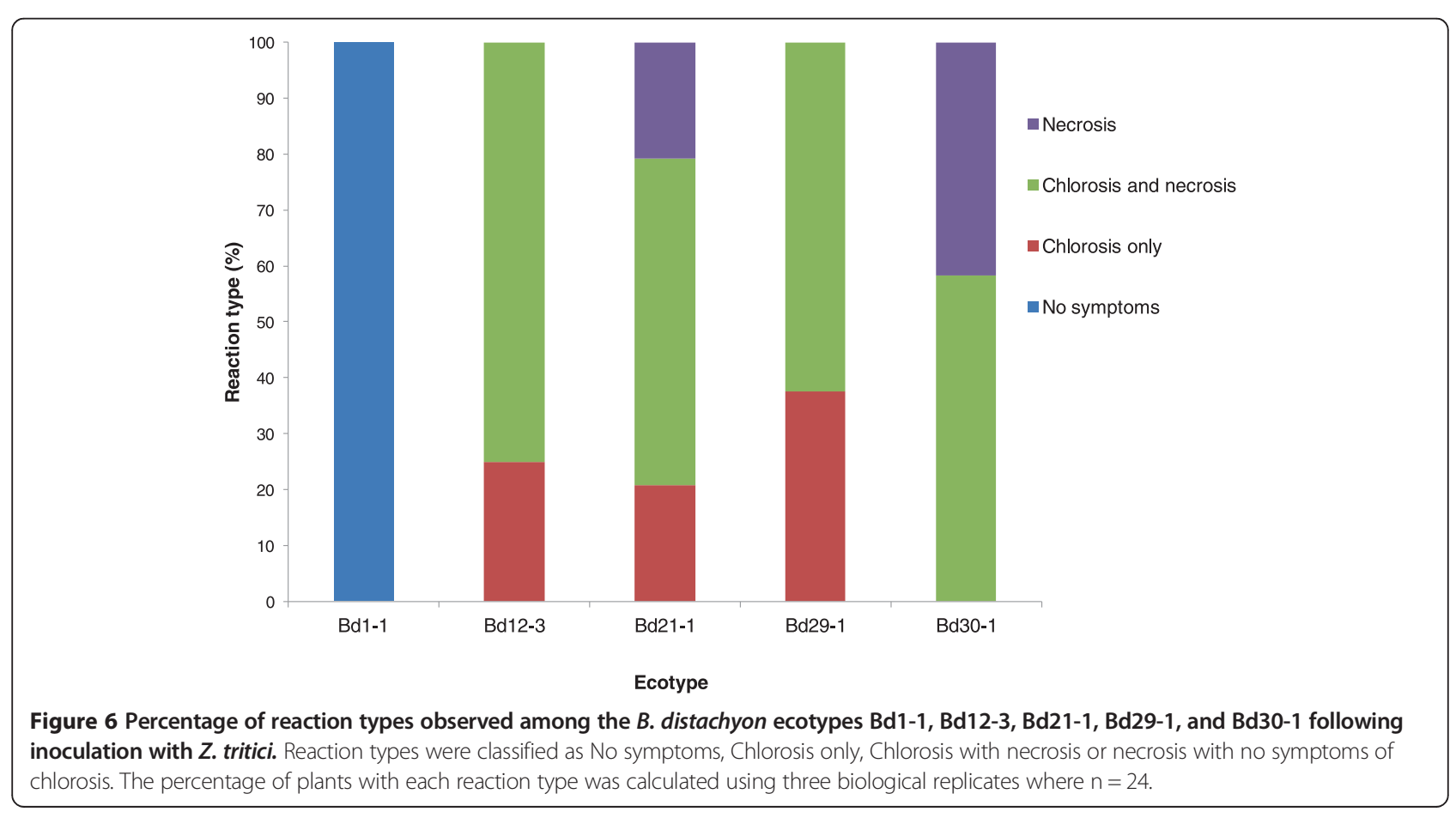


incompatible with only three compatible interactions observed. Further cytological analysis showed that resistant phenotypes blocked Z. tritici at three post-stomatal entry stages which correlated with the sporulation induction phenotypes. Other phenotypes severely restricted post-penetration hyphal growth of $Z$. tritici. Hence, poststomatal entry arrest appears to be the mechanism conferring resistance to $Z$. tritici in $T$. monococcum. The observations made in this study suggest that a pre-penetration mechanism of defence could be operating against $Z$. tritici in $B$. distachyon; though the fungus was detected on epidermal tissue, Koch's postulates for Z. tritici in B. distachyon were not confirmed. Based on our recordings, it appears that germ tubes attached to leaf structures (e.g. trichomes) and traversed epidermal cells. While attempting to gain entry to the host via stoma, their progression was arrested, which paralleled the elicitation of a defence response and the production of defence compounds such as hydrogen peroxide. The use of structures such as trichomes to anchor to and travel from is conceivable as $Z$. tritici can germinate and initiate hyphal growth on essentially almost every surface [3]. B. distachyon also has large trichomes, hence these may act as structures for fungal hyphae to attach to and progress across the leaf surface [47].

The results from our study of the interaction between $Z$. tritici and $B$. distachyon suggest that there is a limited level of compatibility between $B$. distachyon and $Z$. tritici and it is clear that $B$. distachyon is efficient at arresting pathogen ingress. Colonization of substomatal cavities and the intercellular space between mesophyll cells, formation of mature pycnidia in the substomatal cavities and subsequent extrusion of pycnidiospore-bearing cirrhi are the key steps in completing a successful infection cycle [4]. Though fungal sporulation could not be achieved on the ecotypes screened under even the most favourable environmental conditions it is evident that the symptoms observed on $B$. distachyon were that of $Z$. tritici and not of any other disease, due to the precautions taken in the experimental design and procedures.

Differential responses among $B$. distachyon ecotypes to biotic and abiotic stresses have previously been reported $[14,25,28,30,32,48-50]$ indicating that naturally occurring variation may provide insights into mechanisms underlying responses to agronomically important traits. Of significance from this study was that Bd1-1 exhibited a symptomless response to $Z$. tritici strain IPO323. For Bd12-3, Bd21-1 and Bd29-1, necrotic lesions developed following chlorosis of tissues. For Bd30-1, tissues developed an early necrotic response with minimal signs of chlorosis. The interaction between $\mathrm{Bd} 1-1$ and $Z$. tritici strain IPO323 is likely a form of innate immunity to the pathogen, while for the other ecotypes it is possibly a form of induced defence mechanism(s) related to incompatibility between the pathogen and the host.
With the rapid uptake of RNA-Seq [51], the establishment of functional genomics tools such as virus induced gene silencing (VIGS) [52] and the advancements in genome editing techniques such as CRISPR/Cas and TALENs [53], the opportunity to study the genetic mechanisms underlying resistance to $Z$. tritici in both the host and pathogen is an exciting prospect. Encouragement can be taken from the publication of a recent study by [54] which examined the expression profile of $Z$. tritici at the early stages of the interaction with both wheat and B. distachyon; compatible and non-compatible hosts respectively. While expression networks common to both hosts were present, wheat and $B$. distachyon-specific transcripts were also identified, thus presenting the first study of its kind to allow for the identification of whole networks of fungal genes responsible for fungal growth and virulence in both a compatible and non-compatible host of $Z$. tritici. As segregating populations have been developed for most of the diploid inbred lines that have been researched to date $[55,56]$. Bulk segregant analysis of $B$. distachyon mapping populations segregating with differential phenotypes (e.g. Bd1-1 x Bd21-1) could allow for the identification of loci conferring immunity to $Z$. tritici. By combining RNA-Seq with bulked segregant analysis the identification of specific genes underlying these loci should also be possible, enabling examination of the expression profiles for candidate genes of interest while also determining gene function and location within the exome.

\section{Conclusions}

It has been suggested by [25] that verdicts on the host or non-host status of a species cannot be based on observations made within a few ecotypes having a common genetic background, originating from a similar region. In spite of our study being limited with respect to the demographic range of ecotypes and the number of fungal isolates tested, we have identified a differential host response across the ecotypes examined. Based on the physiological assessments described here it can be concluded that the B. distachyon - Z. tritici pathosystem likely involves the activation of host defence mechanisms at the initial stages of the interaction. Incorporating the multitude of resources, tools and knowledge that are now available to the community, we encourage further investigation of $B$. distachyon as a model pathosystem with which to study this economically important cereal pathogen.

\section{Competing interests}

The authors declare that they have no competing interests.

\section{Authors' contributions}

AOD, EM, and FD developed the concepts and designed the research. AOD performed the research and analysed the data with assistance from EM and FD. EM and FD supervised the research. AOD and EM prepared the paper. All authors edited, read and approved the submitted manuscript. 


\section{Acknowledgements}

This study was funded by the Teagasc Core Research Fund and AOD was supported by the Teagasc Walsh Fellowship programme.

\section{Author details}

'Department of Crop Science, Teagasc Research Centre, Oak Park, Carlow, Ireland. ${ }^{2}$ UCD Earth Institute and UCD School of Biology and Environmental Sciences, University College Dublin, Belfield, Dublin 4, Ireland.

\section{Received: 11 August 2014 Accepted: 26 March 2015}

\section{Published online: 09 April 2015}

\section{References}

1. O' Driscoll A, Kildea S, Doohan F, Spink J, Mullins E. The wheat-Septoria conflict: a new front opening up? Trends Plant Sci. 2014. (http://dx.doi.org/ 10.1016/j.tplants.2014.04.011).

2. Cohen L, Eyal Z. The histology of processes associated with the infection of resistant and susceptible wheat cultivars with Septoria tritici. Plant Pathol. 1993;42(5):737-43.

3. Duncan KE, Howard RJ. Cytological analysis of wheat infection by the leaf blotch pathogen Mycosphaerella graminicola. Mycol Res. 2000;104(9):1074-82.

4. Kema G, Yu D, Ritjkenberg F, Shaw MW, Baayen RP. Histology of the pathogenesis of Mycosphaerella graminicola in wheat. Biochem Cell Biol. 1996:86(7):777-86.

5. Rohel EA, Payne AC, Fraaije BA, Hollomon DW. Exploring infection of wheat and carbohydrate metabolism in Mycosphaerella graminicola transformants with differentially regulated green fluorescent protein expression. Mol Plant Microbe Interact. 2001;14(2):156-63.

6. Shetty NP, Kristensen BK, Newman M-A, Moller K, Gregersen PL, Jorgensen HJL. Association of hydrogen peroxide with restriction of Septoria tritici in resistant wheat. Physiol Mol Plant Pathol. 2003;2003(62):333-46.

7. Keon J, Antoniw J, Carzaniga R, Deller S, Ward JL, Baker JM, et al. Transcriptional adaptation of Mycosphaerella graminicola to Programmed Cell Death (PCD) of its susceptible wheat host. Mol Plant Microbe Interact. 2007;20(2):178-93.

8. Shetty NP, Mehrabi R, Lutken H, Haldrup A, Kema GH, Collinge DB, et al. Role of hydrogen peroxide during the interaction between the hemibiotrophic fungal pathogen Septoria tritici and wheat. New Phytol. 2007;174(3):637-47.

9. Ray S, Anderson J, Urmeev F, Goodwin S. Rapid induction of a protein disulfide isomerase and defense-related genes in wheat in response to the hemibiotrophic fungal pathogen Mycosphaerella graminicola. Plant Mol Biol. 2003;53(5):741-54.

10. Rudd J, Kanyuka K, Hassani-Pak K, Derbyshire M, Andongabo A, Devonshire J, et al. Transcriptome and metabolite profiling the infection cycle of Zymoseptoria tritici on wheat (Triticum aestivum) reveals a biphasic interaction with plant immunity involving differential pathogen chromosomal contributions, and a variation on the hemibiotrophic lifestyle definition. Plant Physiology. 2015;167(3):1158-85.

11. Rudd JJ, Keon J, Hammond-Kosack KE. The wheat mitogen-activated protein kinases TaMPK3 and TaMPK6 are differentially regulated at multiple levels during compatible disease interactions with Mycosphaerella graminicola. Plant Physiol. 2008;147(2):802-15.

12. Shetty NP, Jensen JD, Knudsen A, Finnie C, Geshi N, Blennow A, et al. Effects of $\beta-1,3-g$ lucan from Septoria tritici on structural defence responses in wheat. J Exp Bot. 2009;60(15):4287-300.

13. Yang F, Li W, Jørgensen HJL. Transcriptional reprogramming of wheat and the hemibiotrophic pathogen Septoria tritici during two phases of the compatible interaction. PLoS One. 2013;8(11):e81606.

14. Peraldi A, Beccari G, Steed A, Nicholson P. Brachypodium distachyon: a new pathosystem to study Fusarium head blight and other Fusarium diseases of wheat. BMC Plant Biol. 2011;11(1):100.

15. Brenchley R, Spannagl M, Pfeifer M, Barker GLA, D/'Amore R, Allen AM, et al. Analysis of the bread wheat genome using whole-genome shotgun sequencing. Nature. 2012;491(7426):705-10.

16. Eversole K, Feuillet C, Mayer KFX, Rogers J. Slicing the wheat genome. Science. 2014;345(6194):285-7.

17. Nishimura MT, Dangl JL. Arabidopsis and the plant immune system. Plant J. 2010;61(6):1053-66.

18. Pagan I, Fraile A, Fernandez-Fueyo E, Montes N, Alonso-Blanco C, Garcia-Arenal F. Arabidopsis thaliana as a model for the study of plant-virus co-evolution. Philos Trans R Soc Lond B Biol Sci. 2010;365(1548):1983-95.
19. Schlaich NL. Arabidopsis thaliana- the model plant to study host-pathogen interactions. Curr Drug Targets. 2011;12(7):955-66.

20. Bossolini E, Wicker T, Knobel PA, Keller B. Comparison of orthologous loci from small grass genomes Brachypodium and rice: implications for wheat genomics and grass genome annotation. Plant J. 2007;49(4):704-17.

21. Wolfe KH, Gouy M, Yang YW, Sharp PM, Li WH. Date of the monocot-dicot divergence estimated from chloroplast DNA sequence data. Proc Natl Acad Sci U S A. 1989:86(16):6201-5.

22. Paterson AH, Bowers JE, Chapman BA. Ancient polyploidization predating divergence of the cereals, and its consequences for comparative genomics. Proc Natl Acad Sci U S A. 2004;101(26):9903-8.

23. Bevan MW, Garvin DF, Vogel JP. Brachypodium distachyon genomics for sustainable food and fuel production. Curr Opin Biotechnol. 2010;21(2):211-7.

24. Draper J, Mur LA, Jenkins G, Ghosh-Biswas GC, Bablak P, Hasterok R, et al. Brachypodium distachyon. A new model system for functional genomics in grasses. Plant Physiol. 2001;127(4):1539-55.

25. Barbieri M, Marcel TC, Niks RE. Host Status of False Brome Grass to the Leaf Rust Fungus Puccinia brachypodii and the Stripe Rust Fungus P. striiformis. Plant Dis. 2011;95(11):1339-45.

26. Blümke A, Sode B, Ellinger D, Voigt CA. Reduced susceptibility to Fusarium head blight in Brachypodium distachyon through priming with the Fusarium mycotoxin deoxynivalenol. Mol Plant Pathol. 2014. doi:10.1111/ mpp.12203, Article first published online: 22 OCT 2014

27. Falter C, Voigt C. Comparative cellular analysis of pathogenic fungi with a disease incidence in Brachypodium distachyon and Miscanthus x giganteus. Bioenerg Res. 2014;7(3):958-73.

28. Figueroa M, Alderman S, Garvin DF, Pfender WF. Infection of Brachypodium distachyon by formae speciales of Puccinia graminis: early infection events and host-pathogen incompatibility. PLoS One. 2013;8(2):e56857.

29. Goddard R, Peraldi A, Ridout C, Nicholson P. Enhanced disease resistance caused by BRI1 mutation is conserved between Brachypodium distachyon and barley (Hordeum vulgare). Mol Plant Microbe Interact. 2014;27(10):1095-106.

30. Peraldi A, Griffe L, Burt C, McGrann G, Nicholson P. Brachypodium distachyon exhibits compatible interactions with Oculimacula spp. and Ramularia collo-cygni, providing the first pathosystem model to study eyespot and ramularia leaf spot diseases. Plant Pathol. 2014;63(3):554-62.

31. Routledge AP, Shelley G, Smith JV, Talbot NJ, Draper J, Mur LA. Magnaporthe grisea interactions with the model grass Brachypodium distachyon closely resemble those with rice (Oryza sativa). Mol Plant Pathol. 2004;5(4):253-65.

32. Sandoya GV, Buanafina MMO. Differential responses of Brachypodium distachyon genotypes to insect and fungal pathogens. Physiol Mol Plant Pathol. 2014;85(0):53-64.

33. Kema GHJ, Goodwin SB, Hamza S, Verstappen ECP, Cavaletto JR, Van der Lee TAJ, et al. A Combined Amplified Fragment Length Polymorphism and Randomly Amplified Polymorphism DNA Genetic Linkage Map of Mycosphaerella graminicola, the Septoria Tritici Leaf Blotch Pathogen of Wheat. Genetics. 2002;161(4):1497-505.

34. Yang F, Melo-Braga MN, Larsen MR, Jorgensen HJ, Palmisano G. Battle through signaling between wheat and the fungal pathogen Septoria tritici revealed by proteomics and phosphoproteomics. Mol Cell Proteomics. 2013;12(9):2497-508.

35. Goodwin SB, Ben M'Barek S, Dhillon B, Wittenberg AHJ, Crane CF, Hane JK, et al. Finished Genome of the Fungal Wheat Pathogen Mycosphaerella graminicola Reveals Dispensome Structure, Chromosome Plasticity, and Stealth Pathogenesis. PLoS Genet. 2011;7(6):e1002070.

36. Kildea S. Fungicide resistance in the wheat pathogen Mycosphaerella graminicola. Doctoral Thesis. Queen's University Belfast; 2009

37. Suffert F, Sache I, Lannou C. Early stages of septoria tritici blotch epidemics of winter wheat: build-up, overseasoning, and release of primary inoculum. Plant Pathol. 2011;60(2):166-77.

38. King JE, Cook RJ, Melville SC. A review of Septoria diseases of wheat and barley. Ann Appl Biol. 1983;103(2):345-73.

39. Jones DG, Cooke BM. The Epidemiology of Septoria tritici and S. nodorum: I. A tentative key for assessing Septoria Tritici infection on wheat heads. Trans Br Mycol Soc. 1969:53(1):39-IN33.

40. Williams JR, Gareth Jones D. Epidemiology of Septoria tritici and S. Nodorum: VII. Effects of the previous year's infection on disease development and yield in spring wheats. Trans Br Mycol Soc. 1973;61(1):33-9.

41. Brokenshire T. Wheat seed infection by Septoria tritici. Trans Br Mycol Soc. 1975;64(2):331-IN315. 
42. Consolo VF, Albani CM, Berón CM, Salerno GL, Cordo CA. A conventional PCR technique to detect Septoria tritici in wheat seeds. Australas Plant Pathol. 2009;38(3):222-7.

43. Pammel LH, Weems JB, Lamson-Scribner F. Grasses of lowa Part 1. lowa Agric Exp Stn Bull. 1901;54:71-344.

44. Eyal Z. The Septoria/Stagonospora blotch diseases of wheat: past, present, and future. In: Septoria and Stagonospora diseases of cereals: a compilation of global research. Mexico: CIMMY; 1999. p. 177-82.

45. Seifbarghi S, Razavi M, Aminian H, Zare RHE. Studies on the host range of Septoria species on cereals and some wild grasses in Iran. Phytopathol Mediterr. 2009:48:422-9.

46. Jing HC, Lovell D, Gutteridge R, Jenk D, Kornyukhin D, Mitrofanova OP, et al. Phenotypic and genetic analysis of the Triticum monococcum-Mycosphaerella graminicola interaction. New Phytol. 2008;179(4):1121-32.

47. Van Ginkel M, McNab A, Krupinsky A. Septoria and Stagonospora Diseases of Cereals: A Compilation of Global Research. In: Proceedings of the Fifth International Septoria Workshop. Mexico: CIMMYT; 1999.

48. Ayliffe M, Singh D, Park R, Moscou M, Pryor T. Infection of Brachypodium distachyon with Selected Grass Rust Pathogens. Mol Plant Microbe Interact. 2013;26(8):946-57.

49. Barbieri M, Marcel TC, Niks RE, Francia E, Pasquariello M, Mazzamurro V, et al. QTLs for resistance to the false brome rust Puccinia brachypodii in the model grass Brachypodium distachyon L. Genome. 2012;55(2):152-63.

50. Luo N, Liu J, Yu X, Jiang Y. Natural variation of drought response in Brachypodium distachyon. Physiol Plant. 2011;141(1):19-29.

51. Vijay N, Poelstra JW, Künstner A, JB W. Challenges and strategies in transcriptome assembly and differential gene expression quantification. A comprehensive in silico assessment of RNA-seq experiments. Mol Ecol. 2013;22(3):620-34

52. Scofield SR, Huang L, Brandt AS, Gill BS. Development of a virus-induced gene silencing system for hexaploid wheat and its use in functional analysis of the Lr21-mediated leaf rust resistance pathway. Plant Physiol. 2005;138(4):2165-73.

53. Gaj T, Gersbach CA, Barbas III CF. ZFN, TALEN, and CRISPR/Cas-based methods for genome engineering. Trends Biotechnol. 2013;31(7):397-405.

54. Kellner R, Bhattacharyya A, Poppe S, Hsu TY, Brem RB, Stukenbrock EH. Expression profiling of the wheat pathogen Zymoseptoria tritici reveals genomic patterns of transcription and host-specific regulatory programs. Genome Biol Evol. 2014;6(6):1353-65.

55. Garvin DF, Gu YQ, Hasterok R, Hazen SPJ, Enkins G, Mockler TCMLAJ, et al. Development of genetic and genomic research resources for Brachypodium distachyon: a new model system for grass crop research. Crop Sci. 2008;48 (1):69-84.

56. Garvin DF, McKenzie N, Vogel JP, Mockler TC, Blankenheim ZJ, Wright J, et al. An SSR-based genetic linkage map of the model grass Brachypodium distachyon. Genome. 2010;53(1):1-13.

\section{Submit your next manuscript to BioMed Central and take full advantage of:}

- Convenient online submission

- Thorough peer review

- No space constraints or color figure charges

- Immediate publication on acceptance

- Inclusion in PubMed, CAS, Scopus and Google Scholar

- Research which is freely available for redistribution 